\title{
A Synthetic Trivalent Hapten that Aggregates Anti-2,4-DNP IgG into Bicyclic Trimers
}

\author{
Başar Bilgiçer, Demetri T. Moustakas, and George M. Whitesides \\ Department of Chemistry and Chemical Biology, Harvard University 12 Oxford St., Cambridge, MA \\ 02138, U.S.A.
}

\begin{abstract}
This paper describes the synthesis of the trivalent hapten molecule 1 containing three 2,4dinitrophenyl (2,4-DNP) groups, and the use of this molecule to aggregate three molecules of anti-2,4-DNP IgG into a complex with 3:2 stoichiometry $\left(\operatorname{IgG}_{3} \mathbf{1}_{2}\right)$. The equilibrium product $\mathrm{IgG}_{3} \mathbf{1}_{2}$ was generated in $\sim 90 \%$ yield upon mixing $\mathrm{IgG}$ and $\mathbf{1}$; during incubation, thermodynamically unstable, high-molecular-weight aggregates ( $>10^{4} \mathrm{~nm}$ in diameter) form first, and convert subsequently to $\mathrm{IgG}_{3} \mathbf{1}_{2}$. The thermodynamics and the kinetics of the formation of aggregates were studied using size-exclusion high-performance liquid chromatography (SE-HPLC), dynamic light scattering (DLS) and analytical ultracentrifugation (AUC). An analytical model based on multiple species in equilibrium was developed and used to interpret the SE-HPLC data. The aggregate $\mathrm{IgG}_{3} \mathbf{1}_{2}$ was more stable thermodynamically and kinetically than monomeric aggregates of this IgG with monomeric derivatives of 2,4-DNP; this stability suggests potential applications of these aggregates in biotechnology.
\end{abstract}

\section{Introduction}

This paper describes stable aggregates that form on reaction of a monoclonal anti-2,4-DNP $\operatorname{IgG}\left(\operatorname{IgG}{ }^{\mathrm{DNP}}\right)$ with the synthetic trivalent hapten 1 (Scheme 1). Our objective in studying this system of bivalent antibody and trivalent hapten is to understand the thermodynamics governing the aggregation of multivalent biomolecular complexes, and to learn how to design complexes of antibodies and antigens that have well-defined structures and high binding constants. ${ }^{1-7}$ This work is relevant to the design of antibody and antigen-based therapeutics, and may eventually suggest new methods for modulating the biological activities of antibodies in vivo.

Multivalency, the simultaneous binding of multiple ligands on one entity to multiple receptors on another, is important throughout biology. $1,8-16$ Antibodies bind multivalently to their targets; many groups have been studying these interactions in vitro both experimentally and mathematically. ${ }^{17-23}$ Areas of particular interest include cell signaling and activation, response to pathogens, and inflammation. ${ }^{24-27}$

As a model system, we studied a rat IgG antibody that binds with high affinity to 2,4dinitrophenyl (2,4-DNP) groups. The $\mathrm{IgG}^{\mathrm{DNP}}$ is commercially available, and the synthesis of oligovalent antigens presenting 2,4-DNP groups is relatively straightforward. $\mathrm{IgG}^{\mathrm{DNP}}$ also has an unusually high affinity for 2,4-DNP and derivatives; this affinity makes the development of assays for these types of aggregation more straightforward than for more weakly binding systems. Incubation of the trivalent hapten 1 with $\operatorname{IgG}^{\mathrm{DNP}}$ yields stable, bicyclic aggregates 
with stoichiometry $\operatorname{IgG}_{3} \mathbf{1}_{2}$ (Scheme 1 ). We characterized these aggregates using size-exclusion high-performance liquid chromatography (SE-HPLC), analytical ultracentrifugation (AUC) and dynamic light scattering (DLS).

\section{Experimental Design}

\section{Antibody}

The rat anti-2,4-DNP IgG binds to the small molecule hapten 2,4-dinitrophenyl (2,4-DNP) with a monovalent dissociation constant of $K_{d}^{\text {mono }}=8.0 \times 10^{-10} \mathrm{M}{ }^{28}$ This value of $K_{d}$ is atypically high for IgGs, but made this IgG an attractive one for the survey studies of new complexes, since complexes incorporating it were kinetically stable over the time required for analysis by SE-HPLC ( $17 \mathrm{~min})$.

\section{Design of the trivalent hapten}

We designed the trivalent hapten to space the 2,4-DNP groups sufficiently far apart so that the assembly of the bicyclic trimer would be sterically feasible, but close enough together to make it energetically unfavorable for a single molecule of $\mathbf{1}$ to bridge the two Fab arms of a single IgG (Scheme 2). The ethylene glycol linkers connecting the three DNP molecules to the center of this trivalent system are each $3.2 \mathrm{~nm}$ long (when fully extended); hence the longest possible separation between two hapten molecules is $\sim 6.4 \mathrm{~nm}$. The optimum separation of binding sites in an $\mathrm{IgG}$ is approximately $8 \mathrm{~nm}$, although Fab arms can place the binding sites closer. ${ }^{29-31}$

\section{Results}

\section{Thermodynamic Analysis of SE-HPLC data}

We mixed compound $\mathbf{1}$ (prepared as described in the Materials and Methods Section) with $\mathrm{IgG}^{\mathrm{DNP}}$ in phosphate buffered saline (PBS) buffer, allowed the mixture to equilibrate, and analyzed the resulting complexes by SE-HPLC. The concentrations of $\operatorname{IgG}^{\mathrm{DNP}}$ ranged between 0.5 and $2 \mu \mathrm{M}$ in different experiments. During the SE-HPLC serial dilution experiments, we used from 0 to 2 molar equivalents of $\mathbf{1}$ per one equivalent of $\mathrm{IgG}^{\mathrm{DNP}}$, while keeping the antibody concentration constant. Chromatograms of the samples consistently yielded three peaks corresponding to molecular weights of the monomer $\operatorname{IgG}^{\mathrm{DNP}}$, a monocyclic IgG $\mathrm{GNP}^{\mathrm{DNP}}$ dimer, and a bicyclic IgG ${ }^{\mathrm{DNP}}$ trimer (Figure 1). Integrations of areas of these peaks established the relative abundances of each one of these species for each serial dilution (Figure 2). At 0.4 $\mu \mathrm{M} 1$, conversion of $\mathrm{IgG}^{\mathrm{DNP}}$ to the bicyclic $\mathrm{IgG}^{\mathrm{DNP}}$ trimer complex occurred in greater than $90 \%$ yield at $\left[\operatorname{IgG}^{\mathrm{DNP}}\right]=0.6 \mu \mathrm{M}$.

This system follows two distinct regimes of behavior determined by the stoichiometries of $\mathbf{1}$ to $\operatorname{IgG}{ }^{\mathrm{DNP}}$. At stoichiometries of $1: \mathrm{IgG}^{\mathrm{DNP}} \leq 2: 3$, the major product of aggregation we observed on the SE-HPLC corresponded to a molecular weight of three IgGs; this molecular weight suggests the formation of the complex $\operatorname{IgG}_{3} \mathbf{1}_{2}$. At stoichiometries of $\mathbf{1}: \mathrm{IgG}^{\mathrm{DNP}}>2: 3$, SE-HPLC analysis showed three species with molecular weights corresponding to the bicyclic timer complex $\left(\operatorname{IgG} \mathbf{1}_{2}\right)$, monocyclic dimer complex $\left(\operatorname{IgG}_{2} \mathbf{1}_{2}\right)$ and monomer species (IgG, $\operatorname{IgG} \mathbf{1}$ and/ or $\mathrm{IgG1}_{2}$ ). We hypothesize that these smaller aggregates emerge as a result of excess 1 competitively dissociating the complex $\operatorname{IgG}_{3} \mathbf{1}_{2}$ into monocyclic dimer $\operatorname{IgG}_{2} \mathbf{1}_{2}$ and monomeric antibody bound to 1 ( $\operatorname{IgG1}$ and $\left.\operatorname{IgG1} \mathbf{1}_{2}\right)$.

We fitted a model we developed to describe this system $\left(K_{1}, K_{2}\right.$, and $K_{3}$ all have units of $\mathrm{M}^{-1} ; K_{d}$ has units of $\mathrm{M}^{4}$ ) to the data obtained by integrating the peaks of the chromatograms of the SE-HPLC experiments. We propose the following schemes for the formation of the observed complexes in the SE-HPLC experiments: 


$$
\begin{array}{cc}
\mathrm{IgG}+1 \stackrel{K_{1}}{\rightleftharpoons} \mathrm{IgG} 1 & K_{1}=\frac{[\mathrm{IgG} 1]}{[\mathrm{IgG}] \quad[1]} \\
2 \mathrm{IgG} 1 \stackrel{K_{2}}{\rightleftharpoons} \mathrm{IgG}_{2} 1_{2} & K_{2}=\frac{\left[\mathrm{IgG}_{2} 1_{2}\right]}{\left[\begin{array}{ll}
\mathrm{IgG} 1 & 1
\end{array}\right]^{2}} \\
\mathrm{IgG}_{2} 1_{2}+\mathrm{IgG} \stackrel{K_{3}}{\rightleftharpoons} \mathrm{IgG}_{3} 1_{2} & K_{3}=\frac{\left[\mathrm{IgG}_{3} 1_{2}\right]}{\left[\operatorname{IgG}_{2} 1_{2}\right] \quad[\mathrm{IgG}]}
\end{array}
$$

The initial reaction is that combines IgG and 1, and generates IgG1 (equation 1). The next species that forms is $\operatorname{IgG}_{2} \mathbf{1}_{2}$ which is followed by the addition of the third $\operatorname{IgG}$ to this monocyclic antibody dimer, to yield the bicyclic antibody trimer $\operatorname{IgG}_{2} \mathbf{1}_{3}$. The monocyclic dimer $\operatorname{IgG}_{2} \mathbf{1}_{2}$, may form by two paths; one is the reaction of two IgG1 complexes, and the second is the reaction of a doubly ligand bound $\operatorname{IgG}, \operatorname{IgG1} \mathbf{1}_{2}$, with a free molecule of $\operatorname{IgG}$. We assume that the free energy of these two interactions is indistinguishable since the binding sites are approximately independent.

Equation 4 describes the dissociation of the complex to monomers, and the equilibrium constant relating $\operatorname{IgG}_{3} \mathbf{1}_{2}$ to $\operatorname{IgG}$ and $\mathbf{1}$ is described by equation 5:

$$
\begin{gathered}
\mathrm{IgG}_{3} 1_{2} \stackrel{K_{d}}{\rightleftharpoons} 3 \quad \mathrm{IgG}+21 \quad K_{d}=\frac{[I g G]^{3}[1]^{2}}{\left[\operatorname{Ig} G_{3} 1_{2}\right]} \\
K_{d}=\frac{1}{K_{1}^{2} K_{2} K_{3}}
\end{gathered}
$$

Peak areas of SE-HPLC chromatograms were integrated to Lorentzians using the function "fit multi-peaks" available in analysis software Origin. ${ }^{32}$ Using these values with the SOLVE function in Mathematica 5.1, we algebraically solved the equilibrium equations (described in Materials and Methods), and generated polynomial expressions for [IgG1], $\left[\operatorname{IgG} \mathbf{1}_{2}\right]$ and $\left[\operatorname{IgG}_{3} \mathbf{1}_{2}\right]$ as functions of $[\mathbf{1}]_{\text {total }}$, $[\mathrm{IgG}]_{\text {total }}$, and for the equilibrium constants $K_{1}, K_{2}$ and $K_{3}$. Monte Carlo optimization identified optimal values of $K_{1}, K_{2}$ and $K_{3}\left(K_{1}=1.25 \times 10^{9} \mathrm{M}^{-1}\right.$, $K_{2}=1.50 \times 10^{7} \mathrm{M}^{-1}$, and $K_{3}=1.00 \times 10^{10} \mathrm{M}^{-1}$ ); these values fit the data with an R-Square value of $0.988 .33,34$ The predicted curves (Figure 2 ) agree well with the data. When we insert these values into equation 5 , we calculate $K_{d}=4.27 \times 10^{-36} \mathrm{M}^{4}$.

When we conducted the SE-HPLC experiments without prior incubation (injecting the samples within 1 min of mixing 1 with $\operatorname{IgG}^{\mathrm{DNP}}$ ), the chromatograms yielded a new peak that eluted in the void volume. A peak at this retention time corresponds to species that are beyond the resolution limits of the column. Injection of the same sample, after five hours of incubation, established that this peak had disappeared and the only major peak remaining was that which belonged to the $\operatorname{IgG}_{3} \mathbf{1}_{2}$ complex. This observation suggests that the formation of $\operatorname{IgG}_{3} \mathbf{1}_{2}$ proceeds through kinetically formed, thermodynamically less stable, high molecular weight aggregates, which rearrange to the more stable $\operatorname{IgG}_{3} \mathbf{1}_{2}$ with time. We examined the rearrangement of these aggregates in greater detail using DLS.

\section{Dynamic Light Scattering (DLS)}

DLS experiments established the distribution of antibody aggregate sizes during equilibration. We chose DLS for observing the kinetics of aggregate formation during equilibration since DLS provides real-time information about the aggregate size. ${ }^{35,36}$ Experiments began with $3.33 \mu \mathrm{M}(0.5 \mathrm{mg} / \mathrm{mL})$ anti-DNP IgG (PBS buffer $\mathrm{pH} 7.4$ at $\left.25^{\circ} \mathrm{C}\right)$. We added enough $\mathbf{1}$ to form $\mathrm{IgG}_{3} \mathbf{1}_{2}(2.22 \mu \mathrm{M})$, and measured the scattered light at intervals appropriate for the kinetics of 
the equilibration of the aggregates. Each datum was an average over 2 minutes. Anti-DNP IgG alone yielded a single species with a radius of $5.4 \mathrm{~nm}$ on DLS. We did not expect the DLS to differentiate between complexes $\operatorname{IgG}_{2} \mathbf{1}_{2}$ and $\operatorname{IgG}_{3} \mathbf{1}_{2}$ since the hydrodynamic radius of these two species should be very similar. Two minutes after mixing, the solution contained a mixture: a species with an average radius of $11.0 \mathrm{~nm}$ (corresponding to the complexes $\operatorname{IgG}_{3} \mathbf{1}_{2}$ and $\operatorname{IgG}_{2} \mathbf{1}_{2}$ ) and larger species with radii ranging from $1 \times 10^{4}$ to $2 \times 10^{5} \mathrm{~nm}$ corresponding to high molecular weight polymeric aggregates (Figure 3 ). The conversion of $\operatorname{IgG}$ to $\operatorname{IgG}_{3} \mathbf{1}_{2}$ and $\operatorname{IgG}_{2} \mathbf{1}_{2}$ at 2 min was $\sim 60 \%$. After 15-20 min incubation at room temperature, the only observable species (>99\%) was the one with a radius of $11.0 \mathrm{~nm}$. We conclude that the smaller aggregates are the thermodynamic products, derived by equilibration of unstructured, larger aggregates that are the initial products.

\section{Analytical Ultracentrifugation (AUC)}

In order to validate that the thermodynamic product was actually the bicyclic structure $\mathrm{IgG}_{3} \mathbf{1}_{2}$, we also carried out sedimentation equilibrium experiments on a Beckman XL-I ultracentrifuge at rotor speeds of 6,000, 9,000 and 12,000 rpm, at $25^{\circ} \mathrm{C}$ (Figure 4). ${ }^{37} \mathrm{We}$ observed several samples in PBS buffer at $\mathrm{pH} 7.4$, with a range of antibody concentrations from $0.05 \mu \mathrm{M}$ to $0.5 \mu \mathrm{M}$ with $3: 2$ stoichiometric concentrations of $\mathbf{1}$.

Sedimentation equilibrium data were collected for 20 hours for each sample. Comparison of the data at $18 \mathrm{~h}$ and $20 \mathrm{~h}$ into the experiment confirmed that the sample had reached equilibrium. We used the data-analysis software "Origin" with a plug-in supplied by Beckman to fit the AUC data. We fit all the AUC data obtained from several equilibrium experiments at various sample concentrations simultaneously; this procedure yielded an estimated molecular weight of $464 \pm 35 \mathrm{kDa}$ for the $\mathrm{IgG}^{\mathrm{DNP}}$ complex. This result was close to the predicted value of 450 $\pm 12 \mathrm{kDa}$ for the $\mathrm{IgG}_{3} \mathbf{1}_{2}$ species (the molecular weight of an IgG monomer is approximately $150 \pm 4 \mathrm{kDa}$ ). In our hands, AUC experiments carried out with monomeric IgG ${ }^{\mathrm{DNP}}$ yielded a molecular weight of $156 \pm 8 \mathrm{kDa}$.

We fit the individual data to the homogenous species model using the data analysis program Igor (as described in materials and methods). The molecular weight calculated for the complex using these fits validated the molecular weights obtained from fits performed using "Origin". The results of the AUC experiments support the conclusions of the SE-HPLC and DLS experiments.

\section{Thermodynamics and Kinetics}

The DLS experiments established that although monomeric $\operatorname{IgG}^{\mathrm{DNP}}(0.50 \mathrm{mg} / \mathrm{mL}, 3.3 \mu \mathrm{M})$ immediately forms aggregates on addition of $\mathbf{1}$, the system reached thermodynamic equilibrium only after $15-20 \mathrm{~min}$ of incubation at $25^{\circ} \mathrm{C} .{ }^{38}$

In order to measure the rate of ring opening, which we believed to be the slow step of dissociation of the complex, we added a 1000-fold excess of a competitive monovalent hapten $N \varepsilon$-2,4-DNP-Lysine (DNP-Lys) to the preformed bicyclic complex $\operatorname{IgG}_{3} \mathbf{1}_{2}$. We hypothesized that on the opening of one of the rings, the excess DNP-Lys would bind to the free Fab binding site. The resulting aggregate $\operatorname{IgG}_{3} \mathbf{1}_{2} \cdot$ DNP-Lys would have one of the IgGs bound only monovalently to the rest of the complex. A second dissociation would remove the monovalently bound $\mathrm{IgG}$ from the complex, leaving the monocyclic dimer $\operatorname{IgG}_{2} \mathbf{1}_{2}$; this dimeric aggregate would in turn dissociate into monomeric $\operatorname{IgG}$ units by an analogous mechanism. We have examined the counter-intuitive properties of this type of system on dissociation previously using a system comprising oligovalent derivatives of vancomycin and D-Ala-D-Ala. ${ }^{3-5}$ 
The sample was injected on the SE-HPLC immediately after mixing DNP-Lys with $\operatorname{IgG}_{3} \mathbf{1}_{2}$. The chromatogram demonstrated that $\mathrm{IgG}_{3} \mathbf{1}_{2}$ had completely dissociated into monomeric antibody. Assuming that complete dissociation requires 5 half-lives, and that the sample reaches the column after $60 \mathrm{sec}$ of mixing, the lower limit for the pseudo first-order rate constant for dissociation is $\mathrm{k}_{\mathrm{off}} \leq 4.2 \times 10^{-2} \mathrm{sec}^{-1}$. Although this calculated off-rate for the individual $\mathrm{Fab} / \mathrm{DNP}$ interaction suggests a lifetime $\left(\tau_{\text {off }}\right) \leq \sim 0.4 \mathrm{~min}$, the $\mathrm{IgG}_{3} \mathbf{1}_{2}$ complex was kinetically stable over the course of the $\sim 17$ min interval required for SE-HPLC. In another experiment, we slowed the flow rate of the running buffer to $0.1 \mathrm{~mL} / \mathrm{min}$ (instead of our typical $0.5 \mathrm{~mL}$ / $\mathrm{min}$ ) in order to increase the length of time the complex spent on the column by about a factor of five; at this flow rate, the retention time for the $\mathrm{IgG}_{3} \mathbf{1}_{2}$ complex was $\sim 91 \mathrm{~min}$. Integrating the peak areas showed that the complex was still completely intact. We believe the extra kinetic stability of $\mathrm{IgG}_{3} \mathbf{1}_{2}$ (at least a factor of $\sim 225$ relative to IgG $\bullet$ DNP-Lys) reflects the multivalency of the interactions in the aggregate.

\section{Discussion}

We have described the synthesis and characterization of a new type of structured aggregate composed of antibodies and antigens. We infer that the aggregate has a molecular weight that requires it to contain three equivalents of IgG; we assign this aggregate the stoichiometry $\mathrm{IgG}_{3} \mathbf{1}_{2}$ based on the plausibility of this structure, and on the compatibility of this structure with its rapid dissociation on addition of concentrations of a competitive monovalent ligand (DNPLys) above the $K_{d}$ for monomeric DNP. The assembly of this stoichiometrically defined supramolecular structure proceeds in competition with polymerization (as we established through DLS experiments). The structure $\mathrm{IgG}_{3} \mathbf{1}_{2}$ seems to be the most stable species at the concentrations we examined $\left([\operatorname{IgG}]_{\mathrm{o}}=3.3-0.6 \mu \mathrm{M}\right.$ in $\left.[1]_{\mathrm{o}}=2.2-0.4 \mu \mathrm{M}\right)$. We have not yet explored the structural features of $\mathbf{1}$ that influence the stability of $\operatorname{IgG}_{3} \mathbf{1}_{2}$.

In the fully extended conformation, the DNP moieties of the trivalent ligand $\mathbf{1}$ are sufficiently far apart $(\sim 6.4 \mathrm{~nm})$ that they could, in principle, bridge the two binding sites on different Fab arms of a single $\operatorname{IgG}$ (The average Fab distance upon binding is $\sim 8-9 \mathrm{~nm}$, but values as small as $\sim 5.5 \mathrm{~nm}$ have been observed). ${ }^{39}$ Since $\mathrm{IgG}_{3} \mathbf{1}_{2}$ was the major product of aggregation in this system, the formation of the bicyclic complex was more favorable than the binding of a single molecule of 1 to a single antibody (bridging both Fab arms), at the IgG concentrations at which we performed our experiments. Furthermore, we did not observe formation of thermodynamically stable higher aggregates, such as a tricyclic hexameric complex $\left(\operatorname{IgG}_{6} \mathbf{1}_{4}\right)$. The absences of both lower and higher aggregates, and the high yield in conversion to $\operatorname{IgG}_{3} \mathbf{1}_{2}$, suggest that the trimeric antibody aggregate is the most thermodynamically stable structure.

For convenience, in experiments focused more on the physical-organic chemistry of this system than on its biology, we used an antibody ( $\mathrm{IgG}^{\mathrm{DNP}}$ ) with an atypically high monovalent binding constant $\left(K_{d}^{\text {mono }}=8.0 \times 10^{-10} \mathrm{M}\right)$. We approximated the increase in the kinetic stability of $\mathrm{IgG}_{3} \mathbf{1}_{2}$ relative to $\mathrm{IgG}(\mathrm{DNP}-\mathrm{Lys})_{2}$ by estimating the lifetime ( $\left.\tau_{\text {off }}>91 \mathrm{~min}\right)$ of the complex from its stability on the SE-HPLC runs (at $0.1 \mathrm{~mL} / \mathrm{min}$ flow), to be much greater than a factor of 225; this value is a lower limit and a better estimate will require observation of spontaneous dissociation that of a monomeric aggregate. We infer that the kinetic stability of the complex (relative to that of a monomeric aggregate) suggests that multivalency contributes significantly to the stability of $\operatorname{IgG}_{3} \mathbf{1}_{2}$.

$$
\begin{gathered}
\mathrm{IgG}_{3} 1_{2} \stackrel{K_{d 3}}{\rightleftharpoons} \mathrm{IgG}_{2} 1_{2}+\mathrm{IgG} \\
\mathrm{IgG}_{2} 1_{2} \stackrel{d_{2}}{\rightleftharpoons} 2 \quad \mathrm{IgG} \quad 1
\end{gathered}
$$


Equilibrium 6, which is the inverse of equilibrium 3, describes the dissociation of one of the IgGs from the $\mathrm{IgG}_{3} \mathbf{1}_{2}$ complex. The trivalent molecules are still part of a stable dimeric complex $\operatorname{IgG}_{2} \mathbf{1}_{2}$; hence there are two free 2,4-DNP moieties pre-positioned for a free $\operatorname{IgG}$ molecule to bind to. The pre-positioning of the 2,4-DNP moieties provides a higher avidity of a free IgG molecule for $\operatorname{IgG}_{2} 1_{2}$ than for free 2,4-DNP. The equilibrium constants obtained from fitting the SE-HPLC data to our equilibrium model (see materials and methods) yield $\Delta G_{1}^{\circ}=-12.4 \mathrm{kcal} / \mathrm{mol}, \Delta G_{2}^{\circ}=-9.8 \mathrm{kcal} / \mathrm{mol}$ and $\Delta G_{3}^{\circ}=-13.6 \mathrm{kcal} / \mathrm{mol}$ for the equilibria described by equations 1-3. The difference in the free energy of binding between equilibrium 1 and equilibrium 3 is $\Delta \Delta G_{1-3}^{\circ}=-1.2 \mathrm{kcal} / \mathrm{mol}$ (the free energy of binding for monovalent 2,4$\mathrm{DNP}$ to IgG ${ }^{\mathrm{DNP}}$ was calculated from fluorescence quenching data, and is equal to - RT $\ln$ $K_{1}$, where we have calculated $K_{1}$ using our model). This value indicates that binding of an $\mathrm{IgG}^{\mathrm{DNP}}$ to the complex $\operatorname{IgG}_{2} \mathbf{1}_{2}$ is $1.2 \mathrm{kcal} / \mathrm{mol}$ more favorable than its binding to 2,4-DNP.

If we compare the free energy of binding of equilibrium 6 to that of equilibrium 7 (dissociation of cyclic dimer to monomer-DNP complexes from equilibrium 2), we calculate $\Delta \Delta G_{2-3}^{\circ}$ to be $-3.8 \mathrm{kcal} / \mathrm{mol}$. We presume that these interactions are directly comparable, since two hapten moieties bind to two Fab arms simultaneously in both equilibria, and therefore the difference in the binding strengths can be explained in terms of loss of binding entropy.

In equilibrium 7, the Fab arms and the hapten linkers of the dissociated IgG1 complex have more conformational freedom than the free Fab arms and linkers in the $\mathrm{IgG}_{2} \mathbf{1}_{2}$ form. In the case of equilibrium 6 , there is a smaller loss in entropy upon binding than there is for in equilibrium 7, because the DNP moieties for the binding of the third $\mathrm{IgG}$ are pre-positioned by the structure of the complex, and as a result the free energy of binding is substantially more favorable.

Understanding the biophysical attributes of multivalent interactions between biomolecules may help to modify the biological activity of antibodies. Our study once more showed that the bivalency of $\operatorname{IgGs}$ improves both the thermodynamic and kinetic aspects of their binding.

\section{Materials and Methods}

\section{Chemicals}

We purchased $N$-Fmoc-amido-dPEG ${ }_{8}{ }^{\mathrm{TM}_{-}}$-acid from Quanta BioDesign, Ltd, HBTU from Novabiochem, Tris-succinimidyl aminotriacetate from Molecular Probes, Inc., NE-DNPLysine from Sigma-Aldrich Co., $N, N$-diisopropylethylamine (DIEA) from Sigma and Monoclonal rat anti-2,4-DNP IgG antibodies (IgG ${ }^{\mathrm{DNP}}$ ) from Zymed, Inc (Invitrogen). We purchased $N, N$-Dimethylformamide ( $>99.8 \%$ ) and dimethyl sulfoxide (DMSO) (>99.8\%) from EMD; and acetornitrile (>99.8\%) from Mallinckrodt Chemicals. We used $\operatorname{IgG}^{\mathrm{DNP}}$ without further purification. We estimate the purity of the commercial $\mathrm{IgG}^{\mathrm{DNP}}$ to be $>94 \%$, but we did not determine its purity.

\section{Synthesis}

We dissolved $10 \mathrm{mg}$ of $N$-Fmoc-amido- $\mathrm{dPEG}_{8}{ }^{\mathrm{TM}}$-acid in $2 \mathrm{~mL}$ of $N, N$-dimethylformamide and used 1.2 equiv of 2-(1H-benzotriazole-1-yl)-1,1,3,3-tetramethylaminium hexafluorophosphate (HBTU) to activate the carboxlic acid group with 2 equiv of $N, N$-diisopropylethylamine (DIEA) (Scheme 3). After $5 \mathrm{~min}$, we added the activated $\mathrm{N}$-Fmoc-amido- $\mathrm{dPEG}_{8}{ }^{\mathrm{TM}}$-acid to 3 equiv of $N \varepsilon$-DNP-Lysine dissolved in $1 \mathrm{~mL}$ of dimethyl sulfoxide (DMSO). We let this reaction, which gave a quantitative yield (as determined by liquid chromatography), run for $2 \mathrm{~h}$ at room temperature before quenching it by the addition of $4 \mathrm{~mL}$ of $0.1 \%$ trifluoroacetic acid in water. We purified the product 3 via reversed-phase high pressure liquid chromatography (RP-HPLC) as described in the next section. We removed the Fmoc group on the purified product $\mathbf{3}$ using 
$20 \%$ piperidine in DMF for $1 \mathrm{~h}$, isolated the product 2 using RP-HPLC, then lyophilized. We dissolved the lyophilized product 2 in DMF in the presence of 2 equiv of DIEA, and added it drop-wise, over a period of one hour, to a one-third equivalence of Tris-succinimidyl aminotriacetate dissolved in $1 \mathrm{~mL}$ of DMF. After running the reaction overnight, analytical HPLC showed the yield of $\sim 60 \%$ (side products of this reaction are mono and bi substituted aminotriacetate). We purified the product 1 via RP-HPLC and characterized it using MALDITOF (see supp. info.). The calculated molecular weight of $\mathbf{1}\left(\mathrm{C}_{99} \mathrm{H}_{162} \mathrm{~N}_{16} \mathrm{O}_{48}\right)$ was $2344 \mathrm{Da}$; found, $2344 \mathrm{Da}$ on MALDI-TOF (with sodium adduct at $2367 \mathrm{Da}$, and dehydration products at $2326 \mathrm{Da}$ and $2310 \mathrm{Da}$ ).

\section{Purification}

We performed RP-HPLC purifications on a Vydac C18 column $(10 \mathrm{~mm} \times 250 \mathrm{~mm}, 300 \AA ̊$ pore size, $10 \mu \mathrm{m}$ particle size), using linear solvent gradients of $1 \%$ per minute increments in acetonitrile concentration at $2.5 \mathrm{~mL} / \mathrm{min}$ flow rate on a Dynamax Rainin system. We monitored the column eluant using UV absorbances at $218 \mathrm{~nm}$ and $360 \mathrm{~nm}$ with a dual wavelength UV detector, Dynamax model UV-D II.

\section{SE-HPLC}

SE- HPLC measurements were carried out on a Tosoh TSK-GEL G3000SWXL size-exclusion column using a Varian ProStar 400 HPLC system with autosampler. HPLC runs were performed with an isocratic solvent system that was $50 \mathrm{mM}$ phosphate buffer and $370 \mathrm{mM}$ $\mathrm{NaCl}$ (to adjust the ionic strength to $0.475 \mathrm{M}$ ) at $\mathrm{pH} 6.8$, with a $0.5 \mathrm{~mL} / \mathrm{min}$ flow rate. The sample peaks were analyzed by UV-Vis detector, as monitored at $\lambda=218 \mathrm{~nm}$. We kept the concentration of antibody constant in all samples $(0.2,0.6$ or $1 \mu \mathrm{M})$ and incubated the $\operatorname{IgGs}$ with different concentrations of $\mathbf{1}$. We determined the concentrations of our samples using the reported extinction coefficients for IgGs and DNP. We incubated all samples for $12 \mathrm{~h}$ at $4{ }^{\circ} \mathrm{C}$ prior to injection onto the SE-HPLC column.

\section{Dynamic Light Scattering}

DLS experiments were carried out in a $12-\mu \mathrm{L}$ cuvette on a DynaPro dynamic light scattering system at $25^{\circ} \mathrm{C}$. Samples were in $10 \mathrm{mM}$ phosphate (pH 7.40), $137 \mathrm{mM} \mathrm{NaCl}, 2.7 \mathrm{mM} \mathrm{KCl}$, at $3.33 \mu \mathrm{M}(0.5 \mathrm{mg} / \mathrm{mL})$ anti-DNP IgG and $2.22 \mu \mathrm{M} 1$ concentrations in a total volume of 20 $\mu \mathrm{L}$. In order to remove dust particles, prior to mixing anti-DNP IgG with synthetic hapten $\mathbf{1}$, both stock solutions were centrifuged using a Eppendorf Centrifuge ${ }^{\mathrm{TM}}$ model $5415 \mathrm{C}$ at 16,000 rcf (relative centrifugal force) for $20 \mathrm{~min}$.

\section{Analytical Ultracentrifugation}

We estimated the molecular weight of the complex in solution by sedimentation equilibrium on a Beckman XL-I ultracentrifuge. IgG ${ }^{\mathrm{DNP}}$ concentrations in the samples varied from 0.05 to $0.5 \mu \mathrm{M}$. Samples were dissolved in $10 \mathrm{mM}$ phosphate buffer $(\mathrm{pH} 7.40)$, containing $137 \mathrm{mM}$ $\mathrm{NaCl}$ and $2.7 \mathrm{mM} \mathrm{KCl}$. The samples were centrifuged at 6,000, 9,000 and 12,000 rpm for 22 hours at $25{ }^{\circ} \mathrm{C}$ before absorbance scans were performed. Data obtained at $25{ }^{\circ} \mathrm{C}$ were fit globally to an equation that describes the sedimentation of a homogeneous species using dataanalysis programs "Origin" and "Igor" separately. We used the equation (4) below for fits performed using "Igor".

$$
A b s=A^{\prime} \exp \left(H * M\left[x^{2}-x_{o}^{2}\right]\right)+B
$$

where, Abs = absorbance at radius $x, \mathrm{~A}^{\prime}=$ absorbance at reference radius $x_{0}, H=(1-\bar{V} \rho) \omega^{2} /$ $2 R T, V=$ partial specific volume $=0.73 \mathrm{~mL} / \mathrm{g}, \rho=$ density of solvent $=1.0017 \mathrm{~mL} / \mathrm{g}, \omega=$ angular velocity in radians/sec, $M=$ apparent molecular weight, and $B=$ solvent absorbance (blank). 


\section{Equilibrium Model Used Fitting the SE-HPLC Data}

By algebraically rearranging the equilibria in the proposed schemes 1-4 for the formation of the observed complexes in the SE-HPLC experiments, we developed the equations 9-13 to account for the mass balance of each species present in solution at each data point.

$$
K_{1}[\operatorname{IgG}][1]-[\operatorname{Ig} G 1]=0
$$

$$
\left(K_{2}[\operatorname{Ig} G 1]^{2}\right)-\left[\operatorname{Ig} G_{2} 1_{2}\right]=0
$$

$$
\left(K_{3}\left[\operatorname{Ig} G_{2} 1_{2}\right][\operatorname{Ig} G]\right)-\left[\operatorname{Ig} G_{3} 1_{2}\right]=0
$$

$$
[\operatorname{Ig} G]=[\operatorname{Ig} G]_{\text {Total }}-\left[\begin{array}{ll}
\operatorname{Ig} G & 1
\end{array}\right]-2\left[\operatorname{IgG}_{2} 1_{2}\right]-3\left[\operatorname{Ig} G_{3} 1_{2}\right]
$$

$$
[1]=[1]_{\text {Total }}-\left[\begin{array}{ll}
\operatorname{Ig} G & 1
\end{array}\right]-2\left[\operatorname{IgG}_{2} 1_{2}\right]-2\left[\operatorname{IgG} G_{3} 1_{2}\right]
$$

The SOLVE function in Mathematica 5.1 was used to solve the equilibrium equations algebraically, and fit the data from the peak integrations of SE-HPLC experiments, yielding polynomial expressions for [IgG1], $\left[\mathrm{IgG}_{2} \mathbf{1}_{2}\right]$ and $\left[\mathrm{IgG}_{3} \mathbf{1}_{2}\right]$ as functions of $[\mathbf{1}]_{\text {total }}$, [IgG $]_{\text {total }}$ and the equilibrium constants $K_{1}, K_{2}$ and $K_{3}$. Monte Carlo optimization was used to identify optimal $K_{1}, K_{2}$ and $K_{3}$ values $\left(K_{1}=1.25 \times 10^{9} \mathrm{M}^{-1}, K_{2}=2.00 \times 10^{7} \mathrm{M}^{-1}\right.$, and $K_{3}=1.00 \times$ $10^{10} \mathrm{M}^{-1}$ ) that fit the data with an R-Square value of 0.988 . These equilibrium constants fit the data with R-square values of 0.999929 for the monomer data, 0.999992 for the dimer data and 0.999973 for the trimer data.

\section{Supplementary Material}

Refer to Web version on PubMed Central for supplementary material.

\section{Acknowledgements}

This work was supported by the National Institute of Health (GM30367). Demetri T. Moustakas acknowledges support form an NIH postdoctoral fellowship (1 F32 AI068605-0). Authors thank Prof. Krishna Kumar (Tufts University) for his help with analytical ultracentrifugation experiments (NIH 1S10RR017948). Initial studies of multivalent aggregation of IgGs in our group were carried out by Drs. Jerry Yang (now at UCSD) and Lara Estroff (now at Cornell).

\section{References and Notes}

1. Mammen M, Choi SK, Whitesides GM. Angew. Chem.-Int. Edit 1998;37(20):2755-2794.

2. Yang J, Mayer M, Kriebel JK, Garstecki P, Whitesides GM. Angew. Chem.-Int. Edit 2004;43(12): $1555-1558$.

3. Rao JH, Lahiri J, Weis RM, Whitesides GM. J. Am. Chem. Soc 2000;122(12):2698-2710.

4. Rao JH, Lahiri J, Isaacs L, Weis RM, Whitesides GM. Science 1998;280(5364):708-711. [PubMed: 9563940]

5. Rao JH, Whitesides GM. J. Am. Chem. Soc 1997;119(43):10286-10290.

6. Krishnamurthy, VM.; Estroff, LA.; Whitesides, GM. Fragment-based Approaches in Drug Discovery. Jahnke, W.; Erlanson, DA., editors. Wiley-VCH; Weinheim: 2006. p. 11-53.

7. Whitesides GM, Krishnamurthy VM. Q. Rev. Biophys 2005;38(4):385-395. [PubMed: 16817982]

8. Raman R, Raguram S, Venkataraman G, Paulson JC, Sasisekharan R. Nat. Methods 2005;2(11):817824. [PubMed: 16278650]

9. Zhang ZS, Liu JY, Verlinde C, Hol WGJ, Fan EK. J. Org. Chem 2004;69(22):7737-7740. [PubMed: 15498005]

10. Malbon CC. Biochem J 2004;380(Pt 3):831-836. [PubMed: 15025562]

11. Malbon CC. Nat. Rev. Mol. Cell Biol 2005;6(9):689-701. [PubMed: 16231420] 
12. Kitov PI, Bundle DR. J. Am. Chem. Soc 2003;125(52):16271-16284. [PubMed: 14692768]

13. Crothers DM, Metzger H. Immunochemistry 1972;9(3):341-\&. [PubMed: 4113719]

14. Solomon D, Kitov PI, Paszkiewicz E, Grant GA, Sadowska JM, Bundle DR. Org. Lett 2005;7(20): 4369-4372. [PubMed: 16178535]

15. Kitov PI, Shimizu H, Homans SW, Bundle DR. J. Am. Chem. Soc 2003;125(11):3284-3294. [PubMed: 12630884]

16. Fan EK, Zhang ZS, Minke WE, Hou Z, Verlinde C, Hol WGJ. J. Am. Chem. Soc 2000;122(11):26632664.

17. Posner RG, Erickson JW, Holowka D, Baird B, Goldstein B. Biochemistry 1991;30(9):2348-2356. [PubMed: 1900432]

18. Dembo M, Goldstein B. Immunochemistry 1978;15(5):307-313. [PubMed: 700769]

19. Erickson JW, Posner RG, Goldstein B, Holowka D, Baird B. Biochemistry 1991;30(9):2357-2363. [PubMed: 1825785]

20. Subramanian K, Holowka D, Baird B, Goldstein B. Biochemistry 1996;35(17):5518-5527. [PubMed: 8611543]

21. Dembo M, Goldstein B. J. Immunol 1978;121(1):345-353. [PubMed: 78945]

22. Posner RG, Wofsy C, Goldstein B. Math. Biosci 1995;126(2):171-190. [PubMed: 7703593]

23. Schweitzerstenner R, Licht A, Luscher I, Pecht I. Biochemistry 1987;26(12):3602-3612. [PubMed: 3651400]

24. Fewtrell C, Metzger H. J. Immunol 1980;125(2):701-710. [PubMed: 7391576]

25. Hlavacek WS, Faeder JR, Blinov ML, Perelson AS, Goldstein B. Biotechnol. Bioeng 2003;84(7): 783-794. [PubMed: 14708119]

26. Kane P, Erickson J, Fewtrell C, Baird B, Holowka D. Mol. Immunol 1986;23(7):783-790. [PubMed: 2948111]

27. Posner RG, Savage PB, Peters AS, Macias A, DelGado J, Zwartz G, Sklar LA, Hlavacek WS. Mol. Immunol 2002;38(16-18):1221-1228. [PubMed: 12217387]

28. We calculated this equilibrium value for the monovalent hapten DNP-Lys $\left(\mathrm{K}_{d}^{\text {mono }}\right)$ using fluorescence spectrometry.

29. Roux KH, Strelets L, Michaelsen TE. J. Immunol 1997;159(7):3372-3382. [PubMed: 9317136]

30. Roux KH, Strelets L, Brekke OH, Sandlie I, Michaelsen TE. J. Immunol 1998;161(8):4083-4090. [PubMed: 9780179]

31. Strelets L, Roux KH, Brekke OH, Sandlie I, Michaelsen T. FASEB J 1996;10(6):973-973.

32. While fitting the overlapping peaks on the SE-HPLC chromatograms to Lorentzians, we kept the peak position on $\mathrm{x}$-axis (the retention time) as an invariable for each aggregate species. The error bars in Figure 2 are from peak integrations of four separate experiments, each datum is the mean of these measurements and the error bars show the maximum deviation.

33. Raman CS, Allen MJ, Nall BT. Biochemistry 1995;34(17):5831-5838. [PubMed: 7727444]

34. For the initial $K_{l}$ value we used a value of $\mathrm{K}_{d}{ }^{\text {mono }}$ that we calculated using fluorescence quenching of Trp residues on the IgG upon ligand binding.

35. Ahrer K, Buchacher A, Iberer G, Josic D, Jungbauer A. J. Chromatogr. A 2003;1009(1-2):89-96. [PubMed: 13677648]

36. Ahrer K, Buchacher A, Iberer G, Jungbauer A. J. Biochem. Biophys. Methods 2006;66(1-3):73-86. [PubMed: 16458360]

37. Laue TM, Stafford WF. Annu. Rev. Biophys. Biomolec. Struct 1999;28:75-100.

38. In principle, at lower concentrations the antibody/trivalent hapten mixture would reach thermodynamic equilibrium more rapidly.

39. Luedtke R, Owen CS, Karush F. Biochemistry 1980;19(6):1182-1192. [PubMed: 7189409] 


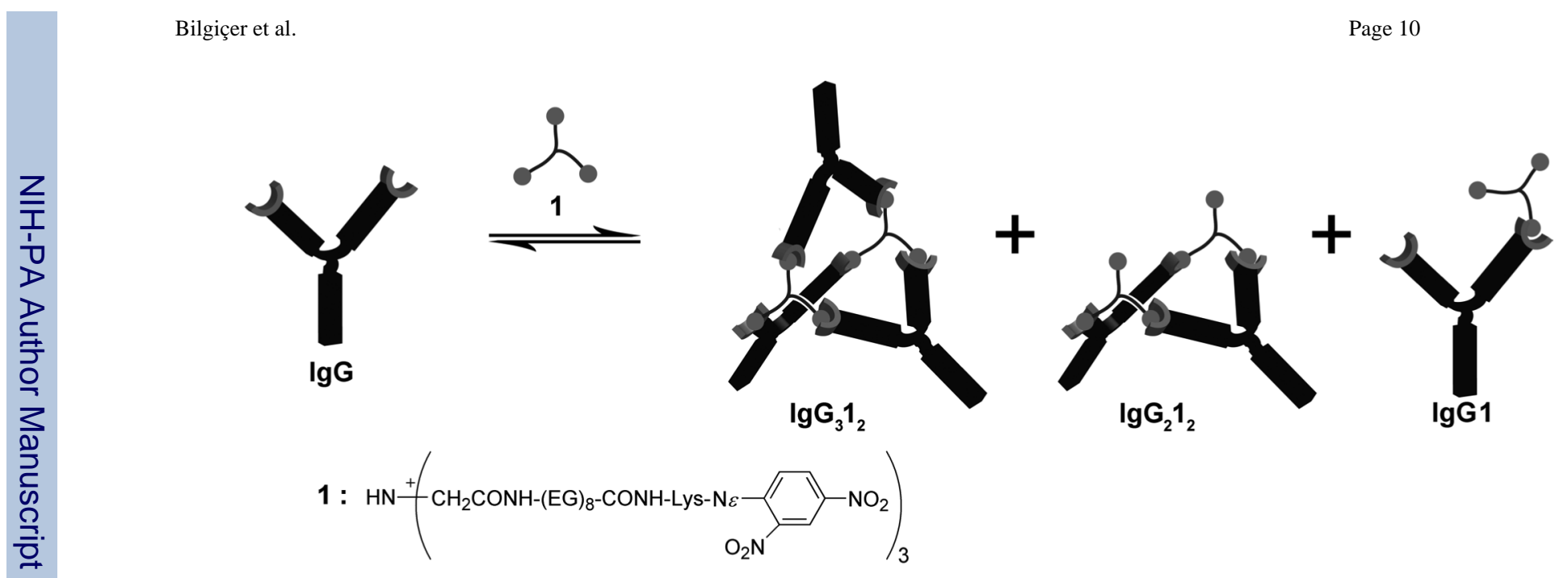

Scheme 1.

The structure proposed for $\operatorname{IgG}_{3} \mathbf{1}_{2}$. 


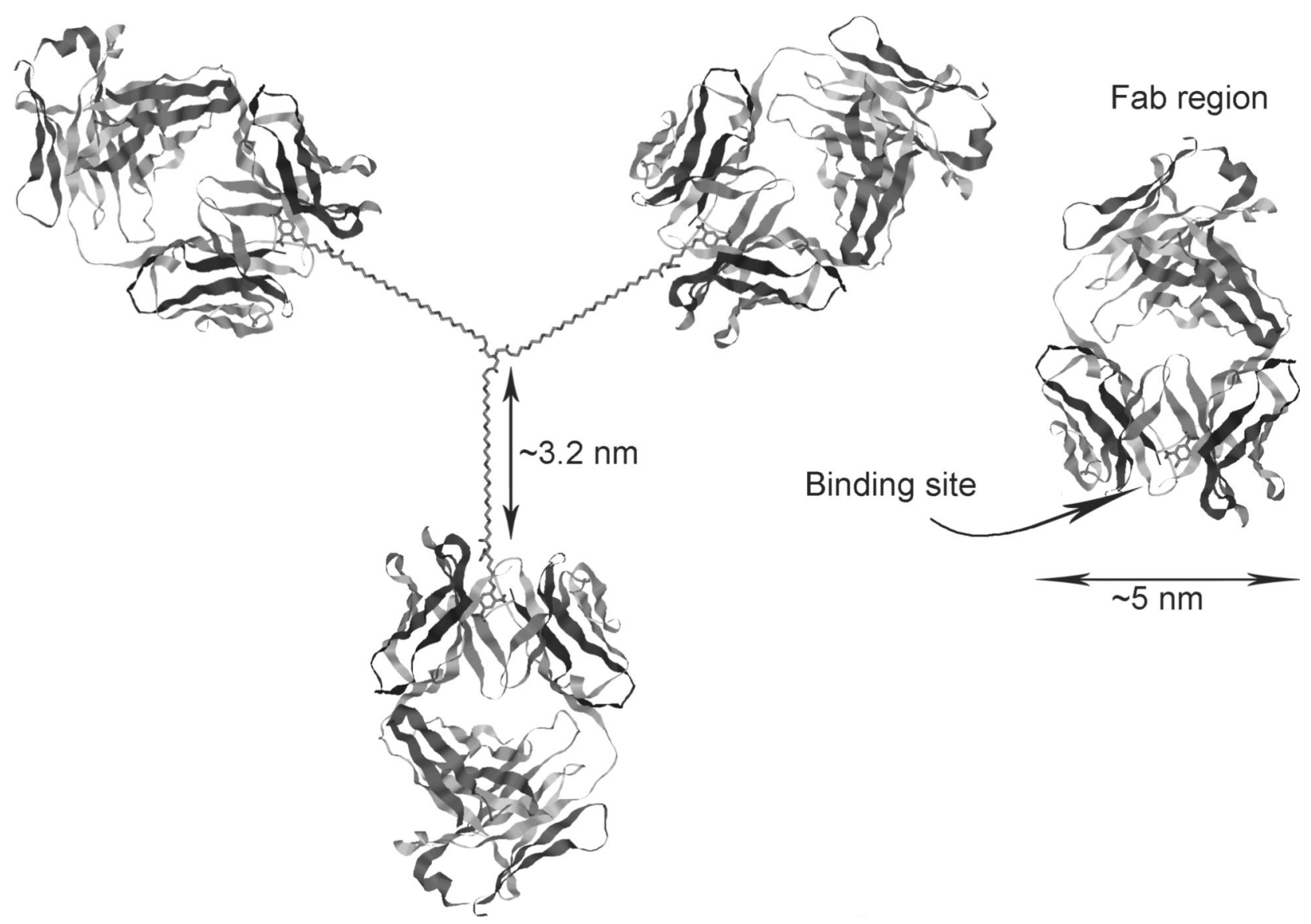

Scheme 2.

Only the Fab regions (PDB ID\# 1A0Q) from three IgG molecules (for clarity) are shown as they are superimposed against a single trivalent hapten molecule $\mathbf{1}$ to estimate the dimensions potentially available in an $\mathrm{IgG}_{3} \mathbf{1}_{2}$ aggregate. The Fab region of an IgG antibody at its widest point is $\sim 5 \mathrm{~nm}$. Each one of the $\mathrm{EG}_{8}$ linkers connecting the antigens to the core of the antigen molecule can extend to $\sim 3.2 \mathrm{~nm}$ in length. In a fully extended form of the $\mathrm{EG}_{8}$ linkers, the Fab regions could adopt the relative distances shown in figure. 

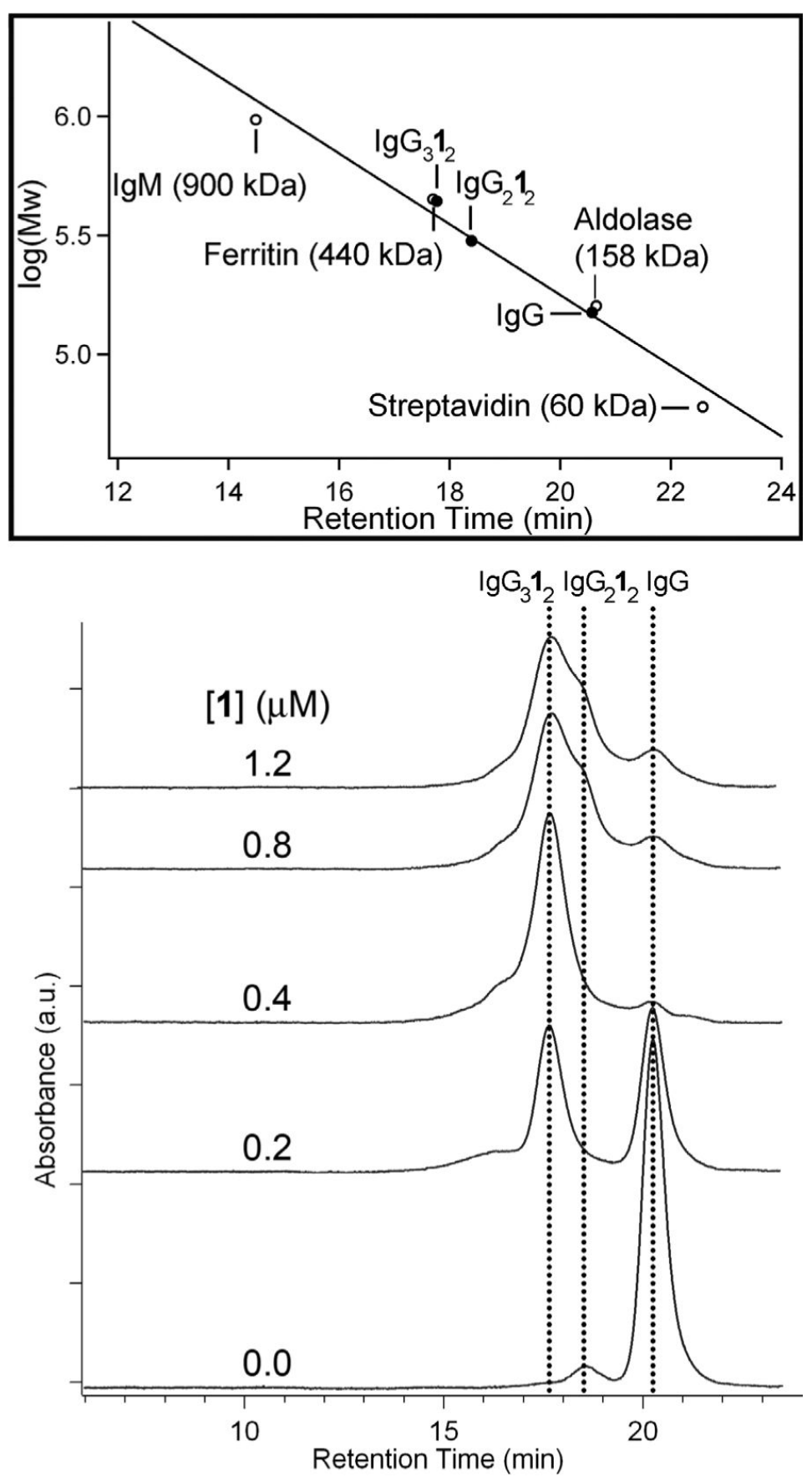

Figure 1.

SE-HPLC chromatograms of complexes of $\operatorname{IgG}^{\mathrm{DNP}}$ and $\mathbf{1}$ (at $[\mathbf{1}]=0.0-1.2 \mu \mathrm{M}$ and $\left[\operatorname{IgG}^{\mathrm{DNP}}\right]$ $=0.6 \mu \mathrm{M})$. The graph at the top calibrates the column against proteins with relevant molecular weights. 


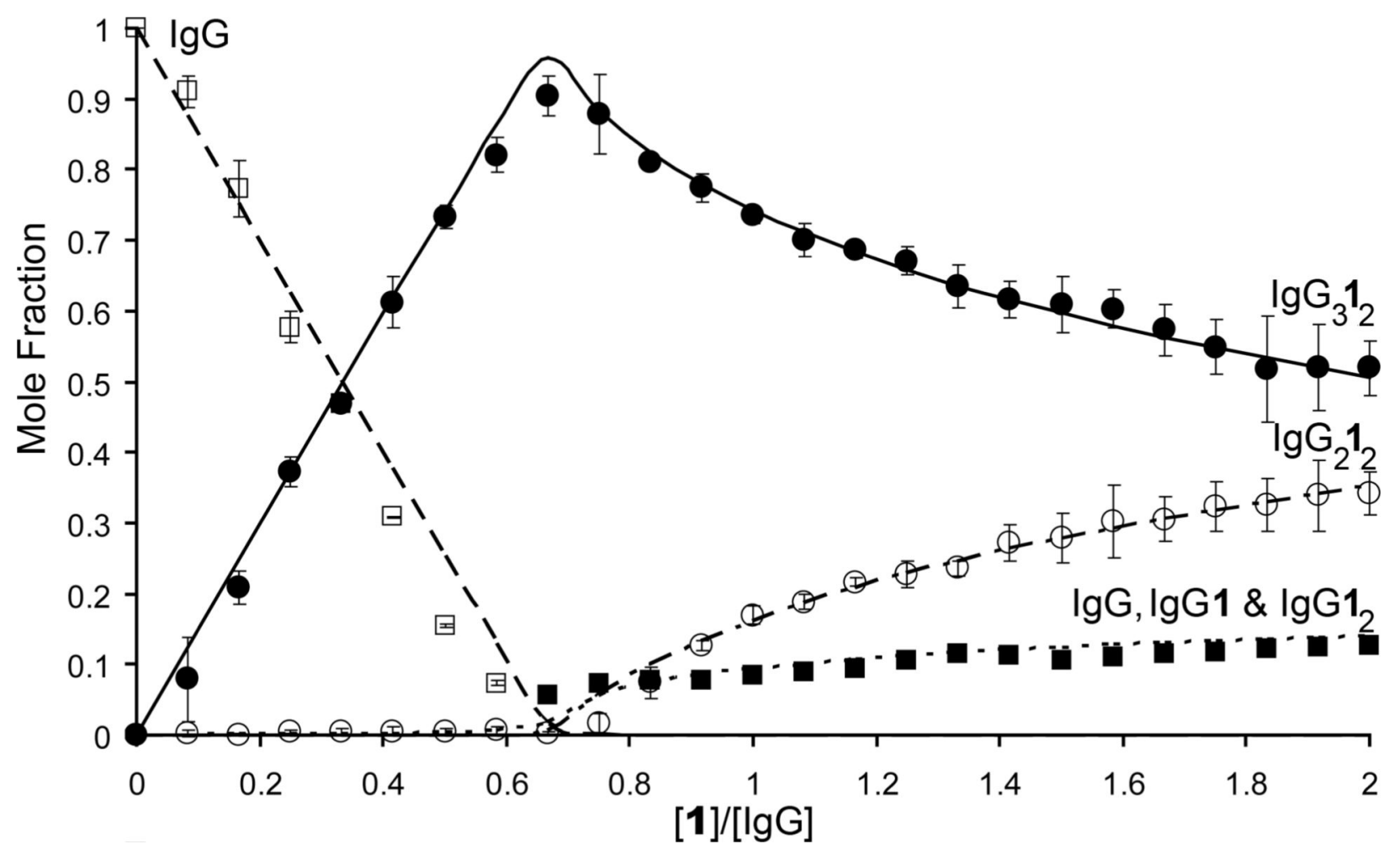

Figure 2.

Mole fraction (lines) produced by fitting the equilibrium model described in the text to the data (markers) from SE-HPLC experiments ([IgG $\left.{ }^{\mathrm{DNP}}\right]$ was kept constant $\left.0.6 \mu \mathrm{M}\right)$. The error bars are from peak integrations of four separate experiments; each datum is the mean of these measurements and the error bars show the maximum deviation. 

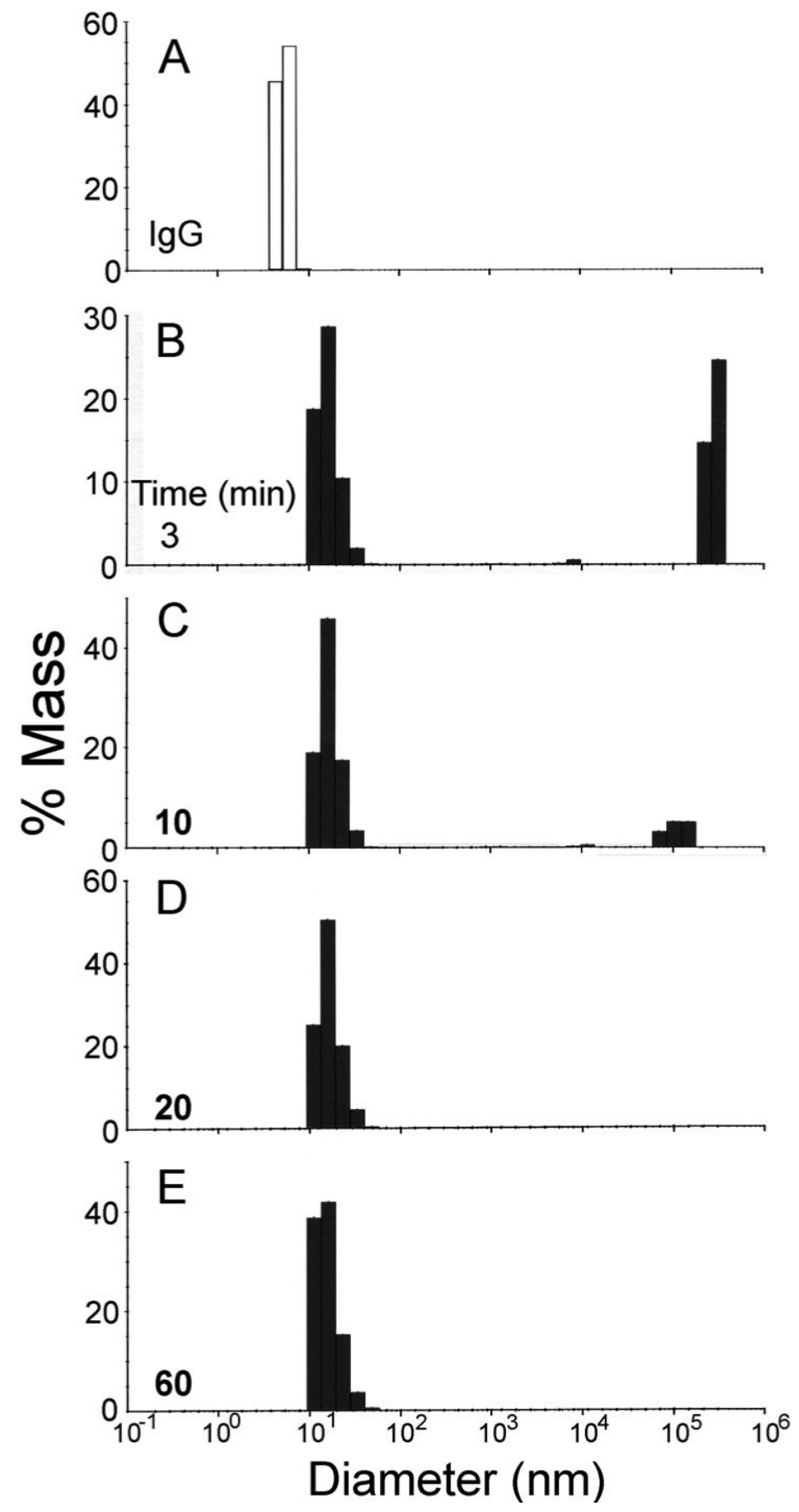

Figure 3.

Diameters of the complexes present in solutions (PBS buffer, $\mathrm{pH}=7.4,25^{\circ} \mathrm{C}$ ) with [1]:[IgG] $=2: 3$, as measured by DLS. $\mathbf{A}$ is $\operatorname{IgG}^{\mathrm{DNP}}$ alone, for $\mathbf{B}$-E incubation intervals are shown on the plot. 


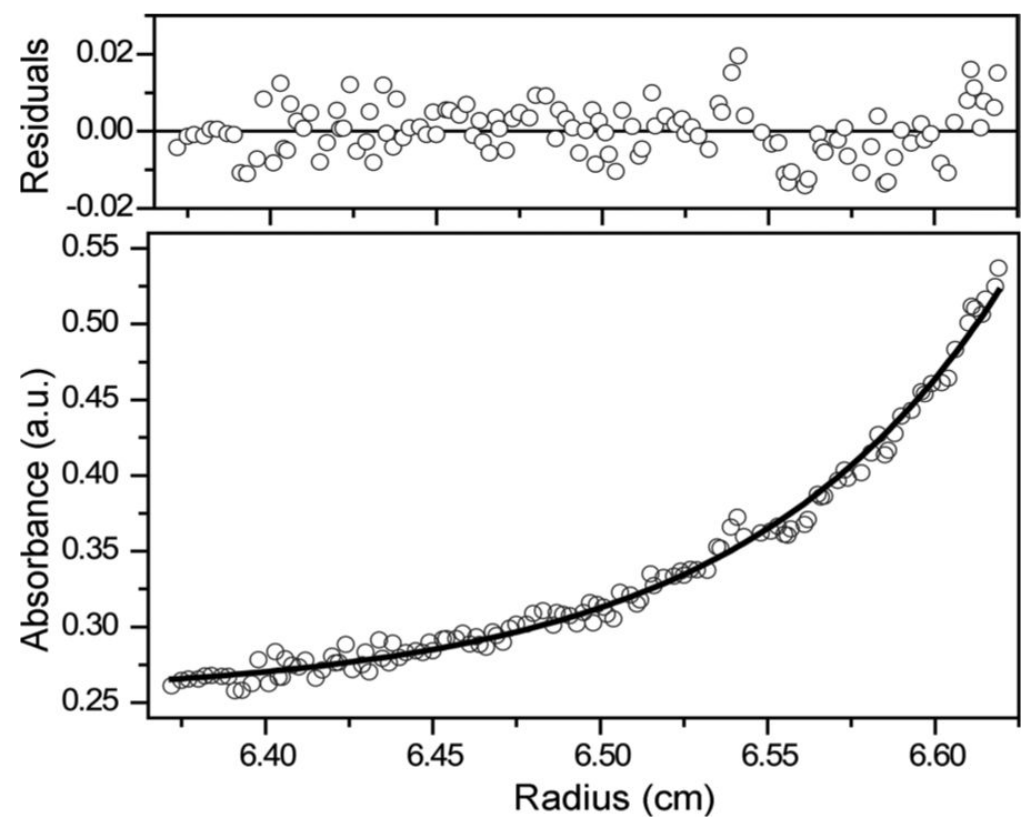

Figure 4.

AUC equilibrium experiment of $0.10 \mu \mathrm{M}$ anti-DNP IgG incubated with $0.067 \mu \mathrm{M} 1$ at $6 \mathrm{~K} \mathrm{rpm}$ as observed at $230 \mathrm{~nm}$ at $25^{\circ} \mathrm{C}$. The hollow circles are experimental data and the line is the fit for a single ideal species. The expected molecular weight is $\sim 450 \pm 12 \mathrm{kDa}$ and the calculated molecular weight is $464 \pm 35 \mathrm{kDa}$. 

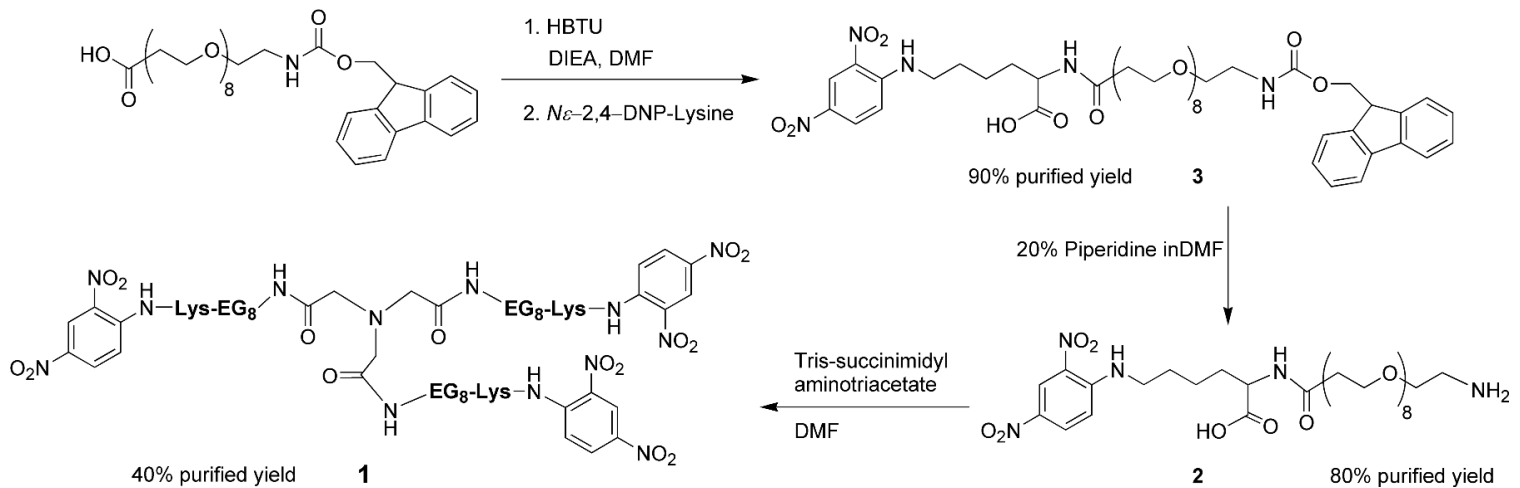

Scheme 3.

Synthesis of 1. 